We reviewed the medical records of 233 patients having electrodiagnostic evidence of polyradiculopathy. Patients with polyneuropathy or incomplete diagnostic evaluation were excluded. A clinical diagnosis was secured in 92 of the 118 remaining patients. Patients were separated into three groups based upon the anatomic location of root involvement: extradural (55), intradural-extraaxial (23), and intraaxial (14). Collectively, patients with intradural-extraaxial disorders had earlier disease onset, shorter symptom duration, and a higher disability score compared with the intraaxial or extradural groups. Pain was an initial complaint in 50 of 55 patients with extradural lesions, 20 of 23 with intradural-extraaxial disease, but only in 4 of 14 with intraaxial involvement. CSF abnormalities and reduced compound muscle action potential amplitudes were more common in the intradural-extraaxial group. We conclude that the anatomic localization of root involvement in patients with polyradiculopathy can be suggested by a combination of clinical, laboratory, and electrodiagnostic features.

Key words: polyradiculopathy $\bullet$ extradural $\bullet$ intraaxial $\bullet$ electrodiagnosis $\bullet$ in tradural-extraaxial

MUSCLE \& NERVE $\quad 13: 63-69 \quad 1990$

\title{
SPECTRUM OF PATIENTS WITH EMG FEATURES OF POLYRADICULOPATHY WITHOUT NEUROPATHY
}

\author{
TIMOTHY K. McGONAGLE, MD, STEVEN R. LEVINE, MD, \\ PETER D. DONOFRIO, MD, and JAMES W. ALBERS, MD, PhD
}

Polyradiculopathy is an electromyographic diagnosis that occurs frequently in the practice of electrodiagnostic medicine. The diagnosis may be suspected but cannot be established by clinical examination alone. The characteristic findings include (1) symptoms and signs referable to multiple roots, (2) normal sensory conduction studies, (3) normal motor nerve conduction studies or slightly reduced motor nerve conduction velocity commensurate with the reduced compound muscle ac-

From the Departments of Neurology and Physical Medicine and Rehabilitation, University of Michigan Medical Center, Ann Arbor, Michigan.

Dr. McGonagle's present address is Research Medical Center, 2316 East Meyer Boulevard, Kansas City, Missouri, 64132.

Dr. Levine's present address is Department of Neurology, Henry Ford Hospital, K-11, 2799 West Grand Boulevard, Detroit, Michigan, 48202.

Dr. Donofrio's present address is Department of Neurology, Bowman Gray School of Medicine, 300 South Hawthorne Road. Winston-Salem, North Carolina 27103

Presented at the 32nd Annual Meeting of the American Association of Electromyography and Electrodiagnosis, Las Vegas, Nevada, October $26-28,1985$

Address correspondence and reprint requests to Dr. Albers at the University of Michigan Medical Center, $1 \mathrm{C} 325 / 0032$ University Hospital, 1500 East Medical Center Drive, Ann Arbor, Michigan 48109-0032.

Accepted for publication October 25, 1988

CCC 0148-639X/90/01063-07\$04.00

(c) 1990 John Wiley \& Sons, Inc. tion potential (CMAP) amplitude, and (4) needle electromyographic abnormalities in a multiple root distribution (multiple root distribution bilaterally or three or more levels ipsilaterally). Findings for the latter consisted of increased insertional activity, abnormal spontaneous activity at rest, and reduced recruitment of increased amplitude, long-duration, polyphasic motor units. Although the most common cause of polyradiculopathy is structural disease of the spine, many other disorders present with identical electrodiagnostic findings. Since involvement anywhere proximal to the dorsal root ganglia, up to and including the anterior horn cell, produces electrodiagnostic evidence of radiculopathy, we reviewed the medical records of the subset of patients with electrodiagnostic evidence of polyradiculopathy without neuropathy to determine the sensitivity and specificity of combined clinical, laboratory, and electrodiagnostic findings in identifying the location of root involvement.

\section{MATERIALS AND METHODS}

Patient records were identified using the electrodiagnosis code file for a 24-month period spanning the years 1982 and 1983. All patients given the diagnosis code for polyradiculopathy $(n=233)$ un- 
derwent initial review. This represented $4.5 \%$ of all electrodiagnostic studies performed during that period. Criteria for inclusion in the study were those stated in the introduction. Patients were excluded who had clinical or electrodiagnostic evidence of a diffuse polyneuropathy. Eleven patients were included with paraspinal muscle abnormalities only (multiple levels bilaterally). All motor and sensory conduction studies had been performed using the standard technique of supramaximal percutaneous stimulation and surface electrode recording with temperature monitoring and extremity warming as was standard laboratory practice. Electromyography was performed using standard concentric needle electrodes.

All records were reviewed with particular attention to symptoms, signs, and medical or surgical histories. Based on ambulatory function, a subjective impairment score was determined for each patient with lower extremity involvement: $1=$ minimal gait impairment; 2 = walk alone with difficulty; 3 = walk only with assistance; and $4=$ wheelchair or bed bound. Laboratory studies were reviewed with special attention to cerebrospinal fluid (CSF) analysis and radiologic studies. Using surgical or radiologic data, each patient was placed into one of three disease groups based upon anatomic location of root involvement: Group I: extradural, Group II: intraduralextraaxial, and Group III: intraaxial.

The data were evaluated in several ways, depending upon the type of variables involved. For parametric data, analysis of variance was used to compare the means of the three patient groups. When differences existed, the subgroup means were compared using multiple Student's $t$-tests and the Bonferroni correction. For nonparametric data, the chi-square test of independence was used to identify differences among the group means. Because some of the analyses were limited by small sample size and subjective interpretation of clinical observations, the results of the statistical evaluations were viewed as reflecting the strengths of the differences between groups rather than as formal tests of specific hypotheses.

\section{RESULTS}

The records of 118 patients satisfied the criteria for polyradiculopathy without neuropathy. One hundred and fifteen patients were excluded either because of electrodiagnostic evidence of a polyneuropathy, absence of new or ongoing denervation, or inadequate diagnostic evaluation or follow-up. Most were removed because of a superimposed polyneuropathy. A specific clinical diagnosis was secured in 92 patients. Table 1 lists by diagnosis the number of patients in each of the three root locations. Extradural lesions accounted for polyradiculopathy in the majority of patients. In most cases, this was secondary to degenerative spine disease at multiple areas. In one quarter of patients, however, polyradiculopathy was attributed to an intradural-extraaxial process. Leptomeningeal carcinomatosis and trauma were the predominant established etiologies in that group. Intraaxial disease accounted for the smallest number of patients with electrodiagnostic incidence of "polyradiculopathy," composed mostly of single or multiple occurrences of rare diseases. In the latter

Table 1. Classification of patients with polyradiculopathy by anatomic localization of root involvement and final clinical diagnosis.

\begin{tabular}{|c|c|}
\hline Root level & $\begin{array}{l}\text { Number of patients } \\
\text { (percentage of total) }\end{array}$ \\
\hline \multicolumn{2}{|l|}{ 1. Extradural lesions } \\
\hline Degenerative spine disease & 18 \\
\hline Lumbar stenosis & 15 \\
\hline Vertebral metastases & 9 \\
\hline Cervical stenosis & 4 \\
\hline Herniated nucleus pulposus & 4 \\
\hline Osteomyelitis & 2 \\
\hline Ankylosing spondylitis & 1 \\
\hline Paget's disease & 1 \\
\hline Lymphoma & 1 \\
\hline Subtotal & $55(47)$ \\
\hline \multicolumn{2}{|l|}{ 11. Intradural-extraaxial lesions } \\
\hline Leptomeningeal carcinomatosis & 9 \\
\hline Traumatic & 6 \\
\hline Arachnoiditis & 3 \\
\hline Sarcoidosis & 1 \\
\hline Recurrent epidermoid tumor & 1 \\
\hline Tuberculous meningitis & 1 \\
\hline Neurolemmoma & 1 \\
\hline Ependymoma & 1 \\
\hline Subtotal & $23(19)$ \\
\hline \multicolumn{2}{|l|}{ 111. Intraaxial lesions } \\
\hline Acute spinal cord ischemia & 3 \\
\hline Multiple sclerosis & 3 \\
\hline Motor neuron disease & 2 \\
\hline Spinocerebellar degeneration & 1 \\
\hline Olivopontocerebellar atrophy & 1 \\
\hline $\begin{array}{l}\text { Posttraumatic anterior horn cell } \\
\text { degeneration }\end{array}$ & 1 \\
\hline $\begin{array}{l}\text { Posttraumatic conus medullaris } \\
\text { syndrome }\end{array}$ & 1 \\
\hline Postpolio muscular atrophy & 1 \\
\hline $\begin{array}{l}\text { Postrabies vaccination } \\
\text { encephalomyeloradiculopathy }\end{array}$ & 1 \\
\hline Subtotal & $14(12)$ \\
\hline IV. Undiagnosed patients & $26(22)$ \\
\hline
\end{tabular}


case, the term polyradiculopathy was used in context to signify involvement of the ventral horns, realizing that disease of the ventral horn is indistinguishable electrodiagnostically from more distal dysfunction of the ventral root.

Comparison of the clinical features among the three groups identified several statistically significant differences (Table 2). Patients with extradural lesions were significantly older $(59.4 \pm 1.9$ years, $P<0.0001)$ than either of the remaining groups. Although patients with intraduralextraaxial lesions had a lower mean age than patients with intraaxial lesions, the difference was not significant. The duration of symptoms prior to diagnosis was shorter in the intradural-extraaxial group, but statistical significance was not reached, primarily because of outliers in the intraaxial group. However, when patients were separated into two subgroups based upon the interval from disease onset to diagnosis (intervals from onset of 3 and 5 months), a greater percentage of patients in the intradural-extraaxial group $(41 \%, P<0.0338$; $82 \%, P<0.0007)$ manifested significantly shorter duration of symptoms than the other groups. In spite of their shorter clinical course, the intradural-extraaxial group also had significantly greater functional impairment $(2.6 \pm 0.3, P<0.004)$ than either of the remaining groups.

For the nonparametric data of clinical symptoms and signs, the only significant differences were the lower percentage of patients with pain in the intraaxial group $(P<0.0001)$ and the lower percentage of patients reporting weakness in the extradural group $(P<0.0188)$. Bowel and bladder dysfunction was twice as common in the intradural-extraaxial and intraaxial groups than the extradural group, but this result was not statistically significant.

Table 3 lists the number and clinical diagnosis of patients without pain who had electrodiagnostic evidence of polyradiculopathy. Notably, 10 of the 14 patients with intraaxial lesions did not experience pain, whereas pain was frequent in the extradural and intradural-extraaxial groups.

Anatomic groups could not be differentiated on the basis of routine hematologic, chemical, serologic, or immunologic studies. Spine radiographs, myelography, and computerized tomography were important in establishing the diagnosis in all patients with identifiable extradural abnormalities, but these studies were frequently normal in patients with intradural-extraaxial and intraaxial disease.

The results of CSF analysis in 45 of the 92 patients is summarized in Table 4. Abnormalities were common in all groups, with CSF protein elevation being the most frequent finding. Although the mean CSF protein did not differ significantly among groups, patients with a protein value exceeding $150 \mathrm{mg} \%$ were statistically more likely to have intradural-extraaxial disease than either of the other two categories $(P<0.03)$. CSF pleocytosis

Table 2. Patients with polyradiculopathy: summary of clinical evaluation.

\begin{tabular}{|c|c|c|c|c|}
\hline & \multicolumn{3}{|c|}{ Anatomical location of pathology } & \multirow[b]{2}{*}{$p$ value } \\
\hline & Extradural $(n=25)$ & Intradural-extraaxial $(n=13)$ & Intraaxial $(n=7)$ & \\
\hline \multicolumn{5}{|l|}{ Patient description } \\
\hline Age at onset (years) & $59.4+1.9^{*}$ & $38.6+4.3$ & $47.1+5.5$ & $0.0001 \dagger$ \\
\hline Time to diagnosis & $3.8+0.8$ & $0.6+0.2$ & $4.6+5.5$ & NS \\
\hline 3 months from onset (\%) & 12 & 41 & 22 & $0.0338 \ddagger$ \\
\hline 5 months from onset $(\%)$ & 29 & 82 & 33 & $0.0007 \ddagger$ \\
\hline Functional impairment & $1.5+0.1$ & $2.6+0.3$ & $2.0+0.6$ & $0.004 \uparrow$ \\
\hline \multicolumn{5}{|l|}{ Symptoms } \\
\hline Weakness (\%) & $58 \S$ & 87 & 90 & $0.0188 \ddagger$ \\
\hline Sensory $(\%)$ & 54 & 65 & 60 & NS \\
\hline Pain $(\%)$ & 90 & 37 & 21 & $0.001 \ddagger$ \\
\hline Bladder/bowel (\%) & 16 & 35 & 30 & NS \\
\hline \multicolumn{5}{|l|}{ Signs } \\
\hline Weakness (\%) & 74 & 88 & 100 & NS \\
\hline Sensory loss (\%) & 67 & 76 & 71 & NS \\
\hline
\end{tabular}

Note: $N S=$ not significant $(\mathrm{P}>0.05)$

*Mean \pm SEM

tAnalysis of variance comparing group means.

fChi-square test of independence.

\$Percentage of patients abnormal within group. 
Table 3. Clinical diagnosis of patients with polyradiculopathy without pain.

\begin{tabular}{lc}
\hline Root level & Number of patients \\
\hline I. Extradural lesions & \\
Metastatic carcinoma to vertebral & 1 \\
$\quad$ body & \\
Spinal stenosis & 4 \\
$\quad$ Subtotal & 5 \\
II. Intradural-extraaxial lesions & 2 \\
Leukemic meningitis & 1 \\
Sarcoidosis & 3 \\
$\quad$ Subtotal & 3 \\
III. Intraaxial lesions & 2 \\
Acute spinal cord ischemia & 1 \\
Multiple sclerosis & 1 \\
Spinocerebellar degeneration & 1 \\
Olivopontocerebellar atrophy & \\
Posttraumatic anterior horn cell & 1 \\
$\quad$ degeneration & 1 \\
Postpolio muscular atrophy & 10 \\
Postrabies vaccination & 18 \\
$\quad$ encephaiomyeloradiculopathy & \\
$\quad$ Subtotal &
\end{tabular}

was recorded in more than half of the patients in the intradural-extraaxial group, nearly twice the prevalence in the intraaxial group $(P<0.0001)$; this abnormality was not found in patients with extradural disease. A CSF pleocytosis exceeding 10 cells/HPF was 3 times more common in the intradural-extraaxial group than the intraaxial group $(P<0.0026)$. Hypoglycorrhachia was observed only in four patients, all having intradural- extraaxial causes for polyradiculopathy [acute lymphocytic leukemia, 2; tuberculous meningitis, 1 ; and sarcoidosis, $1(P<0.02)$ ]. Only patients in the intradural-extraaxial group manifested abnormal CSF cytology $(P<0.0005)$.

As defined, patients in all three groups had similar electrodiagnostic findings, particularly on needle examination. Only slight differences were apparent among the three groups in regard to motor conduction results. The percentage of patients with one or more reduced CMAP amplitudes was greatest in the intradural-extraaxial group, although the group differences were not statistically significant. A unique electrodiagnostic subset included 11 patients with isolated paraspinal muscle abnormalities on needle examination. All of these patients had extradural pathology; none had paraspinal metastasis.

Twenty-six patients with electrodiagnostic findings satisfying the criteria for this study could not be classified into an anatomic category. These included four patients with presumed diabetic polyradiculopathy without neuropathy, for which the anatomic site of pathology is unknown. In 15 patients, no etiology could be secured despite extensive testing. Four of these 15 patients had carcinoma with documented metastases, yet myelography, CSF studies, and follow-up evaluations did not confirm radicular involvement. Seven patients declined evaluation or were lost to follow-up.

Table 5 summarizes the key differential points among the three patient groups with polyradiculopathy without neuropathy.

Table 4. Patients with polyradiculopathy: summary of CSF analysis

\begin{tabular}{lcccc}
\hline & & Anatomical location of pathology & & \\
CSF parameter & Extradural $(n=25)$ & Intradural-extraaxial $(n=13)$ & Intraaxial $(n=7)$ & $p$ value \\
\hline Total protein $(\mathrm{mg} \%)$ & $70+13^{*}$ & $106+23$ & $54+15$ & $\mathrm{NS} \neq$ \\
$\%$ with elevated protein & $48 \dagger$ & 58 & 43 & $\mathrm{NS} \S$ \\
$\%$ with protein $>100 \mathrm{mg} \%$ & 19 & 42 & 13 & $\mathrm{NS}$ \\
$\%$ with protein $>150 \mathrm{mg} \%$ & 7 & 33 & 0 & $0.03 \S$ \\
WBC (per HPF) & $1.4+3$ & $125+26$ & $7.1+5.7$ & $0.0066 \neq$ \\
$\%$ with elevated WBC & 0 & 54 & 29 & $0.0001 \S$ \\
$\%$ with WBC $>$ 10 & 0 & 42 & 14 & $0.0026 \S$ \\
Glucose (mg\%) & $59+2$ & $63+11$ & $62+5$ & $\mathrm{NS}$ \\
$\%$ with glucose <40 mg\% & 0 & 23 & 0 & $0.02 \S$ \\
Positive cytology $(\%)$ & 0 & 54 & 0 & $0.0005 \S$ \\
Any CSF abnormality (\%) & 56 & 69 & 43 & $\mathrm{NS}$ \\
\hline
\end{tabular}

Note: $N S:=$ not significant $(\mathrm{P}>0.05)$.

${ }^{*}$ Mean + SEM.

tPercentage of patients abnormal within group.

$\ddagger$ Analysis of variance comparing group means.

§Chi-square tests of independence. 


\begin{tabular}{|c|c|c|c|}
\hline Differential points & Extradural & Intradural-extraaxial & Intraaxial \\
\hline Age (years) & $59 \pm 2$ & $39 \pm 4$ & $47 \pm 6$ \\
\hline Disease duration (months) & $>5$ & $<5$ & $>5$ \\
\hline Functional disability $(1-4)$ & 1.5 & 2.6 & 2.0 \\
\hline \multicolumn{4}{|l|}{ Symptoms } \\
\hline Weakness & +++ & ++++ & $t+t+$ \\
\hline Sensory loss & +++ & +++ & +++ \\
\hline Pain & ++++ & ++ & + \\
\hline Bowel/bladder dysfunction & + & ++ & ++ \\
\hline \multicolumn{4}{|l|}{ Signs } \\
\hline Weakness & +++ & ++++ & $t+t+$ \\
\hline Sensory Loss & +++ & ++++ & +++ \\
\hline \multicolumn{4}{|l|}{ CSF results } \\
\hline Protein > $100 \mathrm{mg} \%$ & + & ++ & + \\
\hline Pleocytosis & - & +++ & ++ \\
\hline Cytology & - & +++ & - \\
\hline Hypoglycorrhacia & - & + & - \\
\hline Spine imaging studies & ++++ & - & - \\
\hline
\end{tabular}

Note: $-=$ absent in patient group, $+=$ present in $>25 \%$ of patient group, $++=$ present in $25-50 \%$ of patient group, $+++=$ present in $50-75 \%$ of patient group, $++++=$ present in $>75 \%$ of patient group.

\section{Discussion}

Polyradiculopathy is a frequently diagnosed entity in the electromyography laboratory, accounting for approximately $5 \%$ of all patient referrals in our institution. Since the electrodiagnostic findings in polyradiculopathy are similar regardless of the site of root involvement, no specific etiology can be inferred from its discovery. Results of this study of the subset of patients with polyradiculopathy without neuropathy suggest that clues to the anatomic level of root involvement can be derived from careful interpretation of the clinical features, CMAP amplitudes, imaging studies, and CSF results.

Clinical characteristics common to patients with an extradural cause for polyradiculopathy include older age of disease onset, a prolonged and gradually progressive course, and less functional disability compared with patients in the other two groups. Pain is the predominant symptom in this group. Both congenital and acquired degenerative spine diseases are frequent causes of polyradiculopathy in this group, including spinal stenosis and degenerative arthritis. Other etiologies are metastatic carcinoma or local vertebral osteomyelitis with resultat vertebral destruction and epidural root involvement. Polyradiculopathy in one patient was attributed to a paravertebral gutter lymphoma. Other causes for extradural polyradiculopathy reported in the literature, but not identified in any patients included in the study, were neoplastic root infiltration, ${ }^{16}$ subdural abscess, ${ }^{11}$ extradural chordoma ${ }^{13}$ and sarcoma, ${ }^{5}$ meningeal and perineural cyst, ${ }^{30,31}$ and achondroplastic dwarfism. ${ }^{6}$

The sole CSF abnormality in the extradural patient group was moderate protein elevation. The nine patients with metastatic carcinoma to the vertebral bodies did not have CSF pleocytosis or abnormal cytology, confirming integrity of the dura to penetration by neoplastic cells.

Patients in the intradural-extraaxial group were generally younger than patients in the other two groups and presented with a subacute illness which developed over several months. Compared with the extradural group, weakness was more common, but pain occurred less frequently. Functional disability was greatest in this group, probably reflecting the tempo and aggressiveness of the diseases in this category. In more than one-third of these patients, bladder or bowel dysfunction was a prominent complaint. Despite the rapid rate of progression and degree of impairment, the average duration of symptoms prior to establishing the diagnosis was 6 months.

Infiltrative and inflammatory leptomeningeal processes accounted for much of the intraduralextraaxial pathology. ${ }^{1,9,22}$ With respect to meningeal seeding, all but one of the neoplasms were reticuloses. Adenocarcinoma of the lung was the source of infiltration in the one other patient. In several patients, symptoms of polyradiculopathy heralded tumor presentation. The intradural-extraaxial group included six patients with severe 
trauma who subsequently developed a delayed onset, progressive polyradiculopathy associated with pain and weakness in multiple nerve roots remote from the focus of trauma. For the purposes of this study, these patients were considered as having polyradiculopathy secondary to "stretch" injury, although the actual pathophysiology was unknown. Although not observed in this patient group, other etiologies reported to cause intradural-extraaxial polyradiculopathy include infections (parasite, ${ }^{15}$ spirochete, ${ }^{21}$ Lyme disease, ${ }^{24}$ AIDS, ${ }^{7}$ mycoplasma, ${ }^{26,27}$ and viral ${ }^{19,23,33-35}$ ), toxins (phenol, ${ }^{3,32}$ intrathecal penicillin, ${ }^{8}$ intravenous interfer$\mathrm{on}^{2}$ ), postvaccinal, ${ }^{29}$ structural (dural and dermoid cyst, ${ }^{28}$ neurofibroma, ${ }^{19}$ meningioma, ${ }^{28}$ lipoma, ${ }^{28}$ epidermoid, ${ }^{4}$ myelomeningocoele ${ }^{12}$ ), ankylosing spondylitis, ${ }^{10}$ uveoencephalomeningitis, ${ }^{25}$ meningeal seeding from medulloblastoma, ${ }^{28}$ and root avulsion. ${ }^{32,36}$ Many of these diverse disorders have been identified in patients found to have polyradiculopathy subsequent to completion of this study.

CSF studies established the diagnosis in most patients with intradural-extraaxial involvement. Prominent CSF abnormalities included pleocytosis and elevated protein. Positive cytology was reported in more than one-half of these patients, and one-quarter demonstrated hypoglycorrhacia. CSF cytology in some patients with leptomeningeal carcinomatosis was positive only on the third or subsequent lumbar puncture. One patient with diffuse histiocytic lymphoma and a severe polyradiculopathy underwent three CSF analyses prior to discovery of positive cytology on the subsequent lumbar puncture. In this instance, polyradiculopathy was the initial presentation of the lymphoma.

Imaging studies in the intradural-extraaxial group were helpful only in identifying arachnoiditis, although identification of swollen nerve roots or beading would be consistent findings. These were sought but not found.

Intraaxial pathology explained the electrodiagnostic findings of "polyradiculopathy" in $15 \%$ of patients. Symptoms and signs of weakness and sensory loss were the predominant clinical features in these patients. Pain was present in only $21 \%$ of patients in this group, probably explainable by the lack of direct compression of dorsal root fibers or dorsal root ganglion cells by the intraaxial process. CSF studies were abnormal in almost one-half of patients in the intraaxial group, but no feature was distinctive enough to permit separation from the intradural-extraaxial group.
Polyradiculopathy in these patients was attributable to a variety of neurologic conditions, including spinal cord ischemia, multiple sclerosis with ventral horn involvement, degenerative CNS disorders, motor neuron disease, chronic effects of spinal cord trauma, and postvaccination encephalomyeloradiculopathy. Other etiologies for intraaxial polyradiculopathy not observed in this group were transverse myelitis, ${ }^{14}$ malignant atrophic papulosis (Dego's disease), ${ }^{17}$ syringomyelia, ${ }^{14}$ intraspinal neoplasms, ${ }^{20}$ and spinal cord arteriovenous malformations. ${ }^{18}$ In most cases, it could be argued that polyradiculopathy is an improper description of the underlying problem, yet it emphasizes the inability of the electromyographer to more accurately localize the lesion when initially performing the studies.

The results of this study highlight the relative frequency of establishing a diagnosis of polyradiculopathy electrodiagnostically and suggest several clues helpful in the clinical evaluation of patients. Patients with pain without weakness or with isolated paraspinal muscle involvement on needle examination most likely have extradural pathology. Intradural-extraaxial involvement should be considered in patients with progression of symptoms over weeks to months and hypoglycorrachia or positive cytology on CSF analysis. Patients with polyradiculopathy without pain most likely have intraaxial disease. Failure to discover a cause for polyradiculopathy in patients with prominent pain, weakness, and abnormal CSF results should prompt additional CSF analyses in search of evidence for meningeal seeding or inflammation. Whenever meningeal seeding is confirmed, an underlying reticulosis must be sought. Laboratory studies most helpful in identifying an etiology for polyradiculopathy without neuropathy are plain $\mathrm{x}$-ray and CT spine imaging, myelography, and CSF analysis.

The constellation of nerve conduction findings in several patients, i.e., low-amplitude CMAPs with normal amplitude sensory responses, is an uncommon but distinctive electrodiagnostic pattern. In Wilbourn's description of 55 patients with generalized low-amplitude motor responses with normal amplitude sensory responses (GLMNS), almost all of his patients had lower motor neuron involvement within the intraspinal canal, proximal to the dorsal root ganglia, or distally in the terminal nerve fiber or neuromuscular junction. ${ }^{37}$ Included in this group were four patients with polyradiculopathy on the basis of cervical/lumbar canal stenosis or meningeal metastasis. ${ }^{37}$ 
Our inability to classify many patients probably reflected the lack of enthusiasm by the referring clinician in pursuing a specific diagnosis once an electrodiagnosis of polyradiculopathy was rendered. Many patients did not undergo additional testing, in particular, CSF analysis, myelography, and spine CT. Referring clinicians may have accepted polyradiculopathy as a diagnosis in itself rather than a syndrome requiring further investigation.

\section{REFERENCES}

1. Albers JW, Donofrio PD, McGonagle TK: Sequential electrodiagnostic abnormalities in acute inflammatory demyelinating polyradiculoneuropathy. Muscle Nerve. 1985;8:528539 .

2. Bernsen PLJA, Wong-Chung RE, Janssen JTP: Neuralgic amyotrophy and polyradiculopathy during interferon therapy. Lancet. 1985; 1:50.

3. Berry K, Olszewski J: Pathology of intrathecal phenol injection in man. Neurology. 1963;13:152-154.

4. Cantu RC, Wright RL: Aseptic meningitic syndrome with cauda equina epidermoid tumor. I Pediatr. 1968;73:114116.

5. Clarke PRR, Saunders M: Steroid-induced remission of spinal canal reticulum cell sarcoma. J Neurosurg. 1975;42:346348 .

6. Duvoisin RC, Yahr MD: Compressive spinal cord and root syndromes in achondroplastic dwarfs. Neurology. 1962;12:202-207

7. Fidelberg D, Sotrel A, Vogel H, Walker P, Kleefield J, Crumpacker CS: Progressive polyradiculopathy in acquired immune deficiency syndrome. Neurology. 1986;36:912916.

8. Erickson TC, Masten MG, Suckle HM: Complications of intrathecal uses of penicillin. JAMA. 1946;132:561-565.

9. Gardner-Thorpe $C$, Foster JB, Barwick DD: Unusual manifestations of herpes zoster. I Neurol Sci. 1976;28:427-447.

10. Hauge $T$ : Chronic rheumatoid polyarthritis and spondylarthritis associated with neurological symptoms and signs occasionally simulating and intraspinal expansive process. Acta Chir Scand. 1961;120:395-401.

11. Hirson C: Spinal subdural abscess. Lancet. 1965;2:12151217.

12. James CCM, Lassman LP: Spinal dysraphism. An orthopaedic syndrome in children accompanying occult forms. Arch Dis Child. 1960;35:315-327.

13. Kamrin RP, Potanos JN, Pool JL: An evaluation of the diagnosis and treatment of chordoma. $J$ Neurol Neurosurg Psychiatry. 1964;27:157-165.

14. Kaplan PE: Cervical bilateral polyradiculopathy as a manifestation of cervical transverse myelopathy. Electromyogr Clin Neurophysiol. 197;18:159-163.

15. Kawamura J, Kohri Y, Oka N: Eosinophilic meningoradiculomyelitis caused by Gnathostoma spinigerum. Arch Neurol. 1983;40:583-585.

16. LaBan MM, Grant AE: Occult spinal metastases-early electromyographic manifestations. Arch Phys Med Rehabil. $1971 ; 52: 223-226$

17. Label LS, Tandan, R, Albers JW: Myelomalacia and hypoglycorrhachia in malignant atrophic papulosis. Neurology (Cleveland), 1983;33:936-939.

18. Levin KH, Daube JR: Spinal cord infarction: Another cause of "lumbosacral polyradiculopathy." Neurology (Cleveland) 1984;34:389-390.

19. Lichtenstein BW: Neurofibromatosis (Von Recklinghausen's disease of the nervous system). Arch Neurol Psych. 1949;62:822-839.

20. List CF: Intraspinal epidermoids, dermoids and dermal sinuses. Surg Gynecol Obstet. 1941;73:525-538.

21. Merritt HH, Adams RD, Solomon HC: Neurosyphilis. New York, Oxford University Press, 1946, pp 163-166.

22. Nathan PW: Chemical rhizotomy for relief of spasticity in ambulant patients. Brit Med J 1965;1:1096-1100.

23. Oates JK, Greenhouse PRDH: Retention of urine in anogenital herpetic infection. Lancet 1978;1:691-692.

24. Pachner AR, Steere AC: The triad of neurologic manifestations of Lyme disease: meningitis, cranial neuritis, and radiculoneuritis. Neurology 1985;35:47-53.

25. Pattison EM: Uveomeningoencephalitis syndrome (VogtKoyanagi-Harada). Arch Neurol 1965;12:197-205.

26. Ponka A: Central nervous system manifestations associated with serologically verified Mycoplasma pneumoniae infection. Scand I Infect Dis. 1980;12:175-184.

27. Ponka A, von Bonsdorff $M$, Farkkila $\mathrm{M}$ : Polyradiculitis associated with Mycoplasma pneumoniae reversed by plasma exchange. Brit Med J 1983;286:475-476.

28. Russell DS, Rubinstein LJ: Pathology of Tumors of the Nervous System, ed 4. Baltimore, Williams and Wilkins, 1977, pp 30,38, 68, 205-206, 260.

29. Swamy HS, Shankar SK, Chandra PS, Aroor SR, Krishna AS, Perumal VGK: Neurological complications due to beta-propiolactone (BPL)-inactivated antirabies vaccination. Clinical, electrophysiological and therapeutic aspects. I Neurol Sci. 1984;63:111-128.

30. Tarlov IM: Perineurial cysts of the spinal nerve roots. Arch Neurol Psych 1938;40:1067-1074.

31. Tarlov IM: Spinal perineurial and meningeal cysts. $J \mathrm{Neu}$ rol Neurosurg Psychiatry. 1970;33:833-843.

32. Taylor PE: Traumatic intradural avulsion of the nerve roots of the brachial plexus. Brain. 1962;85:579-602.

33. Thomas JE, Howard FM: Segmental zoster paresis-a disease profile. Neurology 1972;22:459-466.

34. Vanneste JAL, Karthaus PPM, Davies G: Acute urinary retention due to sacral myeloradiculitis. I Neurol Neurosurg Psychiatry. 1980;43:954-956.

35. Wadia NH, Irani PF, Katrak SM: Lumbosacral radiculomyelitis associated with pandemic acute haemorrhagic conjunctivitis. Lancet 1973; 1:350-352.

36. Warren J, Gutmann L, Figueroa AF Jr, Bloor BM: Electromyographic changes of brachial plexus root avulsions. $J$ Neurosurg 1969;31:137-140.

37. Wilbourn AJ: Generalized low motor-normal sensory conduction responses: The etiology in 55 patients. Muscle Nerve 1984;7:564-565A. 